\title{
International Journal of Clinical and Diagnostic Pathology
}

ISSN (P): 2617-7226

ISSN (E): 2617-7234

www.patholjournal.com

2020; 3(3): 287-288

Received: 19-05-2020

Accepted: 23-06-2020

\section{Dr. Damodaran AM}

Associate Professor,

Department of Pathology,

Kanachur Institute of Medical

Sciences, Mangalore,

Karnataka, India

Dr. Shreesha Khandige

Professor and Head,

Department of Pathology,

Kanachur Institute of Medical

Sciences, Mangalore,

Karnataka, India
Corresponding Author:

Dr. Shreesha Khandige

Professor and Head,

Department of pathology,

Kanachur Institute of Medical

Sciences, Mangalore,

Karnataka, India

\section{A study of accuracy of fine needle aspiration cytology of thyroid swellings}

\section{Dr. Damodaran AM and Dr. Shreesha Khandige}

DOI: https://doi.org/10.33545/pathol.2020.v3.i3e.296

Abstract

FNAC distinguishes between benign and malignant lesions quite effectively, it is the preoperative screening method of choice worldwide. Its use in recent years has resulted in a significant decrease in the number of surgeries being performed, while increasing the yield of malignant lesions of patients who have undergone surgery. Due to its simplicity, low cost, and absence of major complications, it is the initial investigation in the management of thyroid disease in the hospital. This study is aimed at determining the diagnostic precision of FNAC of thyroid swellings performed and compare with other regions. So this study is intended to study the accuracy of fine needle aspiration cytology of thyroid swellings.

Keywords: FNAC, Thyroid swellings, Thyroid mass, Aspiration cytology, Exclusion Criteria

\section{Introduction}

FNAC is a primary diagnosis of thyroid mass. Clinicians have available, a variety of tests giving anatomical and functional information about the thyroid gland. FNAC, by giving direct morphological information has supplanted most other tests for preoperative evaluation of thyroid nodules ${ }^{[1-5]}$. As FNAC distinguishes between benign and malignant lesions quite effectively, it is the preoperative screening method of choice worldwide. Its use in recent years has resulted in a significant decrease in the number of surgeries being performed, while increasing the yield of malignant lesions of patients who have undergone surgery ${ }^{[6-9]}$. Due to its simplicity, low cost, and absence of major complications, it is the initial investigation in the management of thyroid disease in the hospital. This study is aimed at determining the diagnostic precision of FNAC of thyroid swellings performed and compare with other regions.

\section{Aims and objectives}

To study the accuracy of fine needle aspiration cytology of thyroid swellings.

\section{Materials and methods}

Thirty cases were studied in the Department of Pathology, Kanachur Institute of Medical Sciences. FNAC was done for the thyroid gland and reported.

\section{Inclusion criteria}

Only thyroid disorders.

Exclusion Criteria.

Patients on chemo or radio therapy.

\section{Results}

Table 1: Sex Distribution

\begin{tabular}{|c|c|}
\hline Male & 10 \\
\hline Female & 20 \\
\hline
\end{tabular}

Table 2: Age distribution

\begin{tabular}{|c|c|}
\hline Mean age & Std deviation \\
\hline 37.27 years & 11.18 years \\
\hline
\end{tabular}


Table 3: Diagnosis

\begin{tabular}{|c|c|}
\hline Lesions & Frequency \\
\hline Benign & 21 \\
\hline Suspicious & 2 \\
\hline Malignant & 6 \\
\hline Inadequate sample & 1 \\
\hline
\end{tabular}

Table 4: Distribution of accurate diagnosis

\begin{tabular}{|c|c|}
\hline Benign lesions & \\
\hline Hashimoto Thyroiditis & 03 \\
\hline Subacute Thyroiditis & 01 \\
\hline Colloid goiter & 17 \\
\hline Suspicious & \\
\hline Hurthle Cell Neoplasm & 01 \\
\hline Follicular Neoplasm & 01 \\
\hline Manilgnant Lesions & \\
\hline Papillary Carcinoma & 05 \\
\hline Medullary Carcinima & 01 \\
\hline
\end{tabular}

\section{Discussion}

The accuracy of the FNAC analysis approaches 95\% in the differentiation of the benign nodules from the malignant nodules of the thyroid gland ${ }^{[1]}$. FNAC of the thyroid swellings is reported to have a sensitivity range of $65-98 \%$ and a specificity of $72-100 \%{ }^{[2]}$. In our study, the analysis of the data revealed sensitivity of $65 \%$ and specificity of $99.9 \%$. The results are comparable with the other data from different regions. Kumar et al. in their study on 89 patients with enlarged thyroid gland reported a sensitivity of $77 \%$, specificity of $100 \%$, and diagnostic accuracy of $97.7 \%{ }^{[3]}$. Similarly, a study conducted by Nggada et al. in a teaching hospital in Nigeria reported a sensitivity of $88.9 \%$, specificity of $96.1 \%$, and diagnostic accuracy of $94.2 \%{ }^{[4]}$. Our study and the view of other experts suggest that FNAC is more specific than sensitive in detecting thyroid malignancy and therefore its use, as initial diagnostic test. The false negative FNAC results may occur because of sampling error or misinterpretation of cytology and are of great concern because they indicate the potential to miss a malignant lesion ${ }^{[5]}$. Most authorities are of the opinion that the true false negative rate is below $5 \%$, even if all patients with thyroid FNAC have a histopathological examination ${ }^{[6]}$. In the present study, false negative FNA has occurred in one out of twenty-five (4\%) patients with benign diagnosis. This is consistent with reports in the literature that suggest a false negative rate of $2-7 \%{ }^{[7,8]}$. The false positive rate indicated that a patient with a malignant FNAC result was found on histological examination to have a benign lesion. False positive rate results were uncommon and it was $0 \%$ in our study, which was consistent with other reports that cite FPR results ranging from $0-8 \%{ }^{[7,8]}$. In the present study, the positive predictive value was $99.9 \%$, negative predictive value was $95 \%$, with a diagnostic accuracy of $95.2 \%$, which was similar to the experience of others ${ }^{[9]}$. A negative FNA should never exclude malignancy if there is a strong clinical suspicion. Pitfalls in FNAC of the thyroid as mentioned by Shaha (2000) ${ }^{[14]}$. are: Adequacy of specimens, Accuracy of specimens, accuracy of cytopathological interpretation, Cysts, Follicular lesions, Hurthle cell lesions, and Lymphocytic lesions. The cytopathologists should be aware of the potential diagnostic pitfalls and the interpretational errors that can be reduced further, if the aspirates are obtained from different portions of the nodule with use of other modalities.

\section{Conclusion}

The results comparable with the other data and demonstrate that FNA cytology is a sensitive, specific, and accurate initial diagnostic test for the preoperative evaluation of patients with thyroid swellings.

\section{References}

1. Hall TL, Layfield LJ, Philippe A, Rosenthal DL. Source of diagnostic error in the fine needle aspiration of the thyroid Cancer. 1989;63:718-25.

2. Gharib H. Fine needle aspiration biopsy of thyroid: An appraisal. Ann Int. Med. 1993;118:282-9.

3. Layfield LJ, Reichman A, Bottles K, Giuliano A. Clinical determinants for the management of thyroid nodules by fine needle aspiration cytology, Arch Otolaryngol Head Neck Surgery. 1992;182:717-21.

4. Liel Y, Ariad S, Barchana M. Long term follow up of patients with initially benign thyroid fine needle aspiration Thyroid. 2001;11:775-8.

5. Anderson JB, Webb AJ. Fine Needle Aspiration Biopsy of the cancer Br J Surg. 1987;74:292-6.

6. Leonard N, Mekher DH. To operate or not to operate, the value of fine needle aspiration cytology in the assessment of thyroid swellings, J Clin Pathol. 1997;50:941-3.

7. Mundasad B, Mcallister I, Carson J, Pyper P. Accuracy of fine needle aspiration cytology in diagnosis of thyroid swellings, Internet J Endocrinol. 2006;2.

8. Sclabas GM, Staerkel GA, Shapiro SE, Fornage BD, Sherman SI, Vassillopoulou-Sellin R, et al. Fine Needle Aspiration of thyroid and correlation with histopathology in a contemporary series of 240 patients, Am J Surgery. 2003;186:702-10.

9. Borget I, Vielh P, Leboulleux S, Allyn M, Iacobelli S, Schlumberger $\mathrm{M}$, et al. Assessment of the cost of fine needle aspiration cytology as a diagnostic tool in patients with thyroid nodules, Am J Clin Pathol. 2008;129:763-71.

10. Shaha AR. Controversies in the management of thyroid nodule Laryngoscope. 2000;110:183-93. 